\title{
Clinical and Species Profile of Dermatophytosis in Tertiary Healthcare Centre
}

\author{
A. Deepasri ${ }^{1}$, P.K. Uma Maheswari* and V. Mangayarkarasi \\ Department of Microbiology, SRM Medical College Hospital and Research Centre, \\ Kattankulathur-603203, Chennai, India \\ *Corresponding author
}

A B S T R A C T

\begin{tabular}{|l|}
\hline K e y w o r d s \\
Dermatophytosis, \\
Tinea, \\
Trichophyton, \\
Dermatophytes test \\
medium (DTM), \\
Prevalence
\end{tabular}

Dermatophytosis is the major health problem in worldwide. The three genera of dermatophytes are Microsporum, Trichophyton and Epidermophyton. Among them, Trichophyton spp are the predominant ones causing infection and also associated with recurrence and resistance to antifungal therapy. The dermatophytic infections affect all age groups. The primary aim of this study was to determine the prevalence of dermatophytosis in SRM MCH \& RC between JAN 2017- JAN 2018. This study also aims to study the trend of infections in the adult and paediatric age groups and to observe whether there is any impact of seasonal variation in the distribution of infections. A total of 345 samples were collected from clinically suspected dermatophytosis. Direct microscopy by $\mathrm{KOH}$ and culture on SDA with and without antibiotics, and DTM were done. Of 345 samples collected, $36 \%$ were $\mathrm{KOH}$ positive and $51.9 \%$ were culture positive. More number of cases was observed in the age groups of 16-30 followed by $30-45$ years. Males were more affected compared to females. Tinea corporis was the most common clinical presentation followed by T. cruris. Trichophyton mentagrophytes (58.06\%) was the predominant isolate and then Trichophyton rubrum.

\section{Introduction}

Dermatophytoses is the most common among the various types of cutaneous fungal infection seen in man and animals affecting the skin, hair and nails.

Dermatophytosis is caused by keratinophilic fungi, capable of invading keratinized tissues of skin and its appendages. These are filamentous fungi and they digest keratin by the enzyme keratinases (Jagdish Chander, 2009).
Epidermophyton, Microsporum and Trichophyton are the three main genera of dermatophytes implicated in superficial mycoses (Jagdish Chander, 2009; Vikesh Kumar Bhatia et al., 2014). Epidermophyton and Microsporum are further divided into anthropophilic, zoophilic and geophilic based on their natural habitat. Anthropophilic dermatophytes are associated with infection in humans and rarely animals. Zoophilic dermatophytes cause infection in animals and birds. Geophilic dermatophytes are generally found in soil and take part in decomposition of 
hair, nails, feathers and horns. Dermatophytic infections have been considered to be a major health problem in tropical and the subtropical regions. Reactions due to dermatophyte infections may range from mild to severe degree. The mildness and severity depend on a variety of factors such as the host reactions to the metabolic products of the fungus, virulence of the infecting species or the particular strain, anatomical location of the infection and local environmental factors (Sundar Khadka et al., 2016). They are most prevalent in economically underdeveloped and developing countries where they constitute a major public health problem (Meenakshi Sharma et al., 2012).

This increase may be a result of frequent usage of antibiotics, immunosuppressive drugs and various conditions like obesity, organ transplantations, lymphomas, leukemia and human immunodeficiency virus (HIV) infections. The high prevalence in India is due to favorable climatic conditions like high temperature and humidity. The climatic condition retards evaporation of sweat due to high moisture content of the environment, thus facilitating fungal development. Other factors that favor the high incidence and dissemination of mycoses are poor socio economic conditions, overpopulation, prolonged contact with domestic animals, poor hygiene, synthetic clothing, etc (Carren Sy HAU et al., 2015).

\section{Materials and Methods}

The prospective study was conducted for a period of one year between January 2017 and January 2018 in the Department of Microbiology, in our tertiary healthcare center. Institutional ethics clearance number (1110/IEC/2017).

Three hundred and forty five samples from skin, nail, and hair were collected from the suspected patients of all age groups of both sexes. The skin scrapings were collected from the erythematous growing margins of the lesion with a blunt sterile scalpel after cleaning it thoroughly with $70 \%$ alcohol. The infected nails were clipped, and hair was epilated along with the hair root. The clinical samples were collected in a black envelope and transported to the microbiology laboratory.

The collected samples were subjected to direct microscopic examination by using the $10 \%$ potassium hydroxide $(\mathrm{KOH})$ wet mount for the specimens of skin scales and hair. Nail clippings were kept overnight in $40 \% \mathrm{KOH}$ and then examined under microscope (10X and 40X). All the samples, both $\mathrm{KOH}$ positive and negative were inoculated on Sabourauds dextrose agar with antibiotics (chloramphenicol-50.0mg and gentamicin$5.0 \mathrm{mg}$ ), without antibiotics and Dermatophyte test medium and incubated at two different temperatures $37^{\circ} \mathrm{C}$ and $25^{\circ} \mathrm{C}$; respectively. The cultures were examined periodically for presence of growth, colony morphology, and pigment production. Cultures were incubated for a period of 1 month before discarding them as negative. Slide cultures preparation techniques and LPCB teased mount were performed for identification of specific fungal species. Urease test was also performed to differentiate Trichophyton rubrum and Trichophyton mentagrophytes.

\section{Results and Discussion}

In this study, 345 cases of clinically diagnosed dermatophytosis were studied and the overall prevalence rate of dermatophytic infection was $57.9 \%$. Vikesh Kumar Bhatia et al., (2015) has reported $36.6 \%$ of prevalence, Komal D. Patel et al., (2014) and Gebreabiezgi Teklebirhan et al., (2015) reported $67.2 \%$ and $72.3 \%$ of prevalence of dermatophytic infection respectively. 
Out of 345 patients, males were more predominant $216(62.6 \%)$ compared to females $129(37.3 \%)$ in that paediatric 26 (7.53\%) and adult 319 (92.47\%). More number of cases were observed between age groups of 15-30 years 152(44\%) followed by $30-45$ years $75(21.7 \%)$ (Table 1). Clinical presentations of dermatophytosis observed were $T$. corporis $195(56 \%)$ was the highest one followed by $T$. cruris 55 (15.9\%), $T$. unguium 33 (9.5\%), T. barbae and faciei 29 (8.4\%), T. pedis 23 (6.6\%), T. mannum 3 $(0.8 \%)$ (Table 2) was almost similar when compared with various studies. Three types of specimen collected, skin scraping 308 (89.2\%), nail clipping 33 (9.5\%), Hair 4 $(1.1 \%)$ indicates that skin infection was more compared to nail and hair. This study also revealed that maximum cases of dermatophytic infection were during the month of April to July (55.36\%). The dermatophytic infections were more during the months of April, May and June which highlights the impact of climatic conditions (temperature) with relevance to the enhancement of fungal infections especially during the summer season. Other studies reported that maximum incidence of this infection was in the months of June to August $66.86 \%$ (Reena Goyal et al., 2015).

Out of 345 samples, 125 were $\mathrm{KOH}$ positive and 220 were $\mathrm{KOH}$ negative. Culture positive was 40, among that Trichophyton mentagrophyte (Fig. 1a) 30 (43.4\%) highest one followed by Trichophyton rubrum (Fig. 1b) $9(13 \%)$ and Microsporum species 1 (1.44\%) (Table 3). Out of 40 isolates, 9 isolates were grown on SDA medium and 31 were grown on DTM medium. Various studies had reported that Trichophyton rubrum was the highest one followed by Trichophyton mentagrophytes (Chander Glover et al., 2012; Lakshmi Vasantha Poluri et al., 2015 and Komal D. Patel et al., 2015).

Table.1 Distribution of clinical specimens (age wise and sex wise distribution)

\begin{tabular}{|c|c|c|c|c|c|c|c|}
\hline Age group & \multicolumn{2}{|c|}{ SKIN SCRAPING } & \multicolumn{2}{c|}{ NAIL CLIPPING } & \multicolumn{2}{c|}{ HAIR PLUCKING } & TOTAL \\
\hline Gender & Male & Female & Male & Female & Male & Female & N=345 \\
\hline $\mathbf{0 - 1 5}$ & 14 & 12 & 1 & 0 & 1 & 1 & $29(8.4 \%)$ \\
\hline $\mathbf{1 6 - 3 0}$ & 110 & 35 & 3 & 3 & 1 & 0 & $152(44 \%)$ \\
\hline $\mathbf{3 1 - 4 5}$ & 30 & 30 & 8 & 7 & 0 & 0 & $75(21.7 \%)$ \\
\hline $\mathbf{4 6 - 6 0}$ & 34 & 22 & 2 & 6 & 1 & 0 & $65(18.8 \%)$ \\
\hline$>\mathbf{6 1}$ & 16 & 5 & 2 & 1 & 0 & 0 & $24(6.9 \%)$ \\
\hline TOTAL & $\mathbf{2 0 4 ( 5 9 \% )}$ & $\mathbf{1 0 4 ( 3 0 \% )}$ & $\mathbf{1 6 ( 4 . 6 \% )}$ & $\mathbf{1 7 ( 4 . 9 \% )}$ & $\mathbf{3 ( 0 . 8 \% )}$ & $\mathbf{1 ( 0 . 2 \% )}$ & $\mathbf{3 4 5}$ \\
\hline
\end{tabular}

Table.2 P-value for comparison of sex and clinical presentation

\begin{tabular}{|c|c|c|c|c|c|c|c|c|}
\hline SEX & \multicolumn{8}{|c|}{ Clinical conditions } \\
& $\begin{array}{c}\text { Tinea } \\
\text { corporis }\end{array}$ & $\begin{array}{c}\text { Tinea } \\
\text { cruris }\end{array}$ & $\begin{array}{c}\text { Tinea } \\
\text { unguium }\end{array}$ & $\begin{array}{c}\text { Tinea } \\
\text { pedis }\end{array}$ & $\begin{array}{c}\text { Tinea } \\
\text { barbae \& faciei }\end{array}$ & $\begin{array}{c}\text { Tinea } \\
\text { manuum }\end{array}$ & $\begin{array}{c}\text { Tinea } \\
\text { capitis }\end{array}$ & Value \\
\hline Male & 115 & 51 & 14 & 14 & 15 & 1 & 6 & \\
\hline Female & 80 & 4 & 19 & 9 & 14 & 2 & 1 & 0.0001 \\
\hline Total & $\mathbf{1 9 5}$ & $\mathbf{5 5}$ & $\mathbf{3 3}$ & $\mathbf{2 3}$ & $\mathbf{2 9}$ & $\mathbf{3}$ & $\mathbf{7}$ & \\
\hline
\end{tabular}


Table.3 Distribution of dermatophytes among the culture positive

\begin{tabular}{|c|c|}
\hline Dermatophytes & No of Isolates $(\mathbf{N}=40)$ \\
\hline Trichophyton mentagrophytes & $30(75 \%)$ \\
\hline Trichophyton rubrum & $9(22.5 \%)$ \\
\hline Microsporum species & $1(2.5 \%)$ \\
\hline
\end{tabular}

Figure.1 a) Trichophyton mentagrophytes grown in SDA medium and rat tail filament observed in LPCB Mount b) Trichophyton rubrum grown in DTM medium and teardrop microconidia observed in LPCB mount

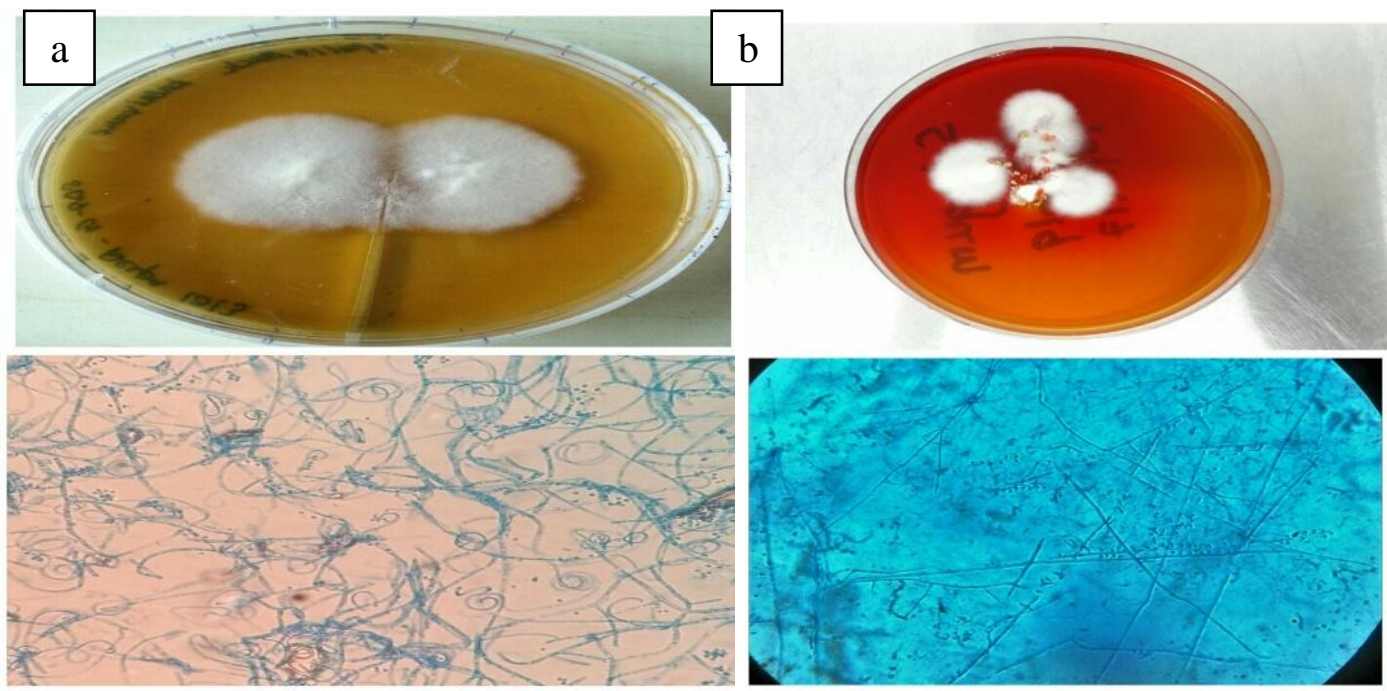

Prevalence rates for onychomycosis vary between 3 to $5 \%$. However, in the general population a few reports suggest a higher prevalence of even up to $26 \%$ (Chander Grover et al., 2012). In this present study the overall prevalence of onychomycosis was $9.5 \%$ and more commonly observed in females.

In our study we observed that, out of 345 patients, recurrent cases were 108 (31.3\%), patients with obesity were $33(9.5 \%)$, patients with diabetes were $60(17.3 \%)$ and 99 (28.6\%) cases were previously exposure to azole drugs.

To conclude, Dermatophytosis is the commonly encountered fungal infection in all over the world. The culture positive rate was less due to the cases with previous history of exposure to azole drugs. Rate of recurrence were observed in few infection due to resistance to therapy in which the patients fail to follow the full course of treatment. Males were infected more because of their heavy physical activity.

All culture positive isolates were grown both on SDA and DTM. DTM was the useful medium for primary isolation and appearance of growth was within 7-10 days of inoculation. In this present study, we noticed that the dermatophyte isolates produced various pigmentation on the reverse side of the SDA plates. The pigmentation in the dermatophyte test medium was due to alteration in the $\mathrm{pH}$ of the medium so, the entire DTM medium turned to dark pink in colour. 


\section{References}

Carren Sy HAU et al., (2015), Immunoresponses in dermatomycoses, Journal of Dermatology; 42: 236-244

Chander Grover, Ananta Khurana. (2012). Onychomycosis: Newer insights in pathogenesis and diagnosis. Indian Journal of Dermatology, Venereology, and Leprology | May-June 2012 | Vol 78 | Issue 3.

Gebreabiezgi Teklebirhan and Adane Bitew. (2015). Prevalence of Dermatophytic Infection and the Spectrum of Dermatophytes in Patients Attending a Tertiary Hospital in Addis Ababa, Ethiopia, International Journal of Microbiology. Article ID 653419, 5 pages.

Jagdish Chander, A Textbook of Medical Mycology, $3^{\text {rd }}$ edition, (2009) Chapter 10 -Dermatophytoses, page no 122 145.

Komal D. Patel, Jaysukh D. Mangukiya, Mahendra M. Vegad. (2015). Prevalence of dermatophytes in skin, hair and nail at tertiary care hospital at Ahmdeabad. National Journal of Medical Research. Volume 5, Issue 4.

Lakshmi Vasantha Poluri, Jyothi P Indugula, Sai L Kondapaneni. (2015). Clinicomycological Study of Dermatophytosis in South India. Journal of Laboratory physicians. volume 7, 7:84-9.

Meenakshi Sharma, Richa Sharma. (2012). Profile of Dermatophytic and Other Fungal Infections in Jaipur. Indian
Journal of Microbiology. 52(2):270274

Prabhat Kiran Khatri1, Dileep Kachhawa1, Vinod Maurya1, Saroj Meena2, Archana Bora2, (2017) Antifungal Resistance Pattern among Dermatophytes in Western Rajasthan. International Journal of Current Microbiology and Applied Sciences. Volume 6 Number 7 pp. 499-509.

Reena Goyal, Geeta Tinna, Anjali Gupta and B P Sharma. (2015) Epidemio Clinico - Microbiological Study of Dermatophytosis in North West Region of Rajasthan, India. International Journal of Current Microbiology and Applied Sciences. 4(11): 394-399.

S.Grover and P. Roy, (2003). Clinicomycological profile of superficial mycosis in a hospital in North-East India, Medical Journal Armed Forces India, vol. 59, no. 2, pp.114-116.

Sundar Khadka et al., (2016) Clinicomycological Characterization of Superficial Mycoses from a Tertiary Care Hospital in Nepal. Dermatology Research and Practice, Volume 2016, Article ID 9509705, 7 pages

Vikesh kumar Bhatia, P. Sharma. (2014). Epidemiology studies on Dermatophytosis in human patients in Himachal Pradesh India. Springer open journal. 3:134. Pp. 2-7.

\section{How to cite this article:}

Deepasri, A., P.K. Uma Maheswari and Mangayarkarasi, V. 2018. Clinical and Species Profile of Dermatophytosis in Tertiary Healthcare Centre. Int.J.Curr.Microbiol.App.Sci. 7(05): 22212225. doi: https://doi.org/10.20546/ijcmas.2018.705.259 